\title{
Identidad práctica en Aristóteles y Leibniz
}

\author{
ROBERTO CASALES-GARCÍA* \\ Universidad Popular Autónoma del Estado de Puebla (México) \\ roberto.casales@upaep.mx \\ LIVIA BASTOS ANDRADE** \\ Universidad Popular Autónoma del Estado de Puebla (México) \\ Livia.bastos@upaep.mx
}

\begin{abstract}
Resumen
El presente trabajo de investigación tiene por objetivo reconstruir la noción de identidad práctica tanto en Aristóteles como en Leibniz, a fin de mostrar en qué medida el hannoveriano es deudor del Estagirita y en qué medida se distingue una propuesta de la otra. Para lograr esto hacemos dos cosas: por un lado, analizamos la noción aristotélica de praxis y de agencia moral a la luz de su noción de habituación; por otro lado, damos cuenta de la dimensión práctica que el hannoveriano adscribe a su noción de identidad personal, a partir de sus nociones de conscientia y cualidad moral.
\end{abstract}

Palabras clave: praxis, identidad personal, habituación, Aristóteles, Leibniz.

\section{Practical Identity in Aristotle and Leibniz.}

\begin{abstract}
The purpose of this research is to reconstruct the notion of practical identity in both Aristotle and Leibniz, in order to show to what extent, the Hanoverian is indebted with Aristotle and to what extent one proposal can be distinguished from the other. To achieve this we do two things: on the one hand, we analyze the Aristotelian notion of praxis and moral agency trough his notion of habituation; on the other hand, we notice the practical dimension that Leibniz assigns to his notion of personal identity, based on his notions of conscientia and moral quality.
\end{abstract}

Key words: praxis, personal identity, habituation, Aristotle, Leibniz:

* Doctor en Filosofía por la Universidad Nacional Autónoma de México (UNAM). Profesor investigador y director académico de la Facultad de Filosofía de la UPAEP. Miembro de la Red Iberoamericana Leibniz, de la North American Kant Society, del Centro de Estudios de Familia y Sociedad, y del Sistema Nacional de Investigadores (nivel I). Autor de libros como: Avatares de la contemplación y otros ensayos críticos de filosofía (2019), Imperativo categórico y carácter. Una introducción a la filosofía práctica de Kant (2019), Justicia, amor e identidad en la ontología monadológica de Leibniz. (2018), entre otras publicaciones.

** Doctora en Filosofía por la Pontificia Universidad de la Santa Cruz en Roma. Es psicóloga por la Universidad de Coimbra en Portugal. Desde el 2019, es miembro de la Facultad de Filosofía de la UPAEP y del Sistema Nacional de Investigadores de México (SNI). Es Directora de la Revista Metafísica y Persona, Consultora del International Institute of Culture and Gender Studies, Miembro de la Sociedad Latinoamericana Peirce, Miembro del Comité Científico de la Revista Correlatos y Miembro del Claustro Académico del Centro de Bioética de la UPAEP. 
La discusión contemporánea sobre la identidad personal, uno de los problemas heredados principalmente por la filosofía moderna, comprende no sólo una amplia diversidad de problemáticas, sino también una variedad de posibles perspectivas que parten de distintos niveles de análisis. Entre las perspectivas más destacadas se encuentra la propuesta de Christine M. Korsgaard, quien ha popularizado la noción de identidad práctica al reflexionar "sobre el modo en el que debe ser concebida la identidad propia del sujeto de praxis o, si se prefiere, la identidad de la persona, en su carácter de agente" (Vigo, 2016: 13). Una persona es un agente moral, en opinión de Korsgaard, en la medida en que posee una estructura reflexiva de autocomprensión, en virtud de la cual los agentes son capaces de reflexionar sobre aquellas valoraciones de carácter normativo que subyacen a cada una de sus acciones, de modo que, "cuando usted delibera, es como si hubiera algo por encima de todos sus deseos, algo que es usted, y que elige conforme a cuál desea actuar", de modo que "considera que el principio o ley por el cual determina sus acciones lo expresa a usted mismo" (Korsgaard, 2000: 129). La identidad práctica, en este sentido, "es una concepción de nosotros mismos bajo la cual nos valoramos y descubrimos que vale la pena vivir nuestras vidas y vale la pena realizar nuestras acciones" (Korsgaard, 2011: 25-26).

Esta caracterización de la identidad personal en términos de una valoración o descripción práctica de carácter normativo es plausible, en opinión de Ana Marta González, en la medida en que "percibimos, siquiera de forma confusa, una relación entre lo que somos $\longrightarrow$ lo que pensamos que somos - y lo que hacemos /debemos hacer; o, si se prefiere, lo que somos -o lo que pensamos que somos- y lo que, precisamente por eso, no debemos hacer" (González, 2018: 178-179). Todo sujeto de praxis, acorde con Korsgaard, relaciona consigo mismo una serie de concepciones con las que se identifica, justificando cierto tipo de motivos y obligaciones, inclinándonos a actuar de tal o cual forma. Así, por ejemplo, "quien se comprende y valora a sí mismo como padre, actuará o se verá inclinado a actuar de determinada manera, por caso, dando preferencia a sus obligaciones para con sus hijos frente a determinados intereses o gustos personales" (Vigo, 2016: 13). Cada una de estas concepciones, en consecuencia, da cuenta de porqué realizamos determinados actos y nos adjudicamos determinadas obligaciones, de modo que, como sostiene Korsgaard, "nuestras razones expresan nuestra identidad, nuestra naturaleza; nuestras obligaciones emanan de lo que esa identidad prohíbe" (Korsgaard, 2000: 130). 
Acorde con la propuesta de Korsgaard, dado que una acción intencional es aquella que es atribuible a un agente como su autor, esto es, cuya causalidad es adscrita al sujeto de la praxis, se sigue que "siempre que eliges una acción - siempre que tomas control de tus propios movimientos- estás constituyéndote a ti mismo como el autor de esa acción y decidiendo, por tanto, quién quieres ser", de modo que, en cuanto agente racional, "te confrontas a la tarea de hacer algo de ti mismo" (Korsgaard, 2009: xi-xii). La noción de identidad práctica, en este sentido, 'hace referencia al modo en que el 'sujeto' de praxis se comprende a sí mismo, vale decir, se hace cargo 'ejecutivamente' de su propia identidad, como el individuo que precisamente es" (Vigo, 2010: 130). Para que esto sea posible, según Steven Galt Crowell, no basta con que la realidad del sujeto se corresponda con tal o cual concepción, sino que es necesario que éste incorpore dicha descripción en la autocomprensión de su identidad, tal y como se observa en el caso de la paternidad, ya que sólo en la medida en que me hago cargo ejecutivamente de mi paternidad, como parte de mi autocomprensión, logro "satisfacer las demandas normativas de ser padre" (2010: 60).

Aquellas concepciones que el sujeto de la acción integra en la comprensión de su propia identidad, así, contienen los estándares normativos o principios prácticos que hacen posible la agencia moral, dotando al agente de cierta unidad (Korsgaard, 2009: 7). De modo que la noción de identidad práctica, en su carácter normativo, da cuenta de aquello que motiva a los sujetos de praxis a actuar de una determinada forma, la cual se relaciona con la manera en que "el agente se comprende a sí mismo, vale decir, se hace cargo ejecutivamente de sí, como el individuo que precisamente es y tiene que ser" (Vigo, 2016: 13). Se trata, pues, de una noción que - si bien es cierto no está desarrollada al interior del corpus aristotélico y que, tal y como la caracteriza Korsgaard, no termina de

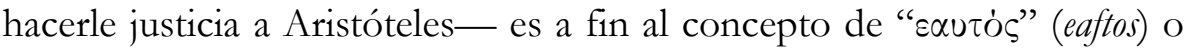
"sí mismo", con el cual es acorde el obrar el virtuoso: "el hombre virtuoso está de acuerdo consigo mismo" (Aristóteles, 1985b [EN, IX 4, 1166a 12] $)^{1}$. También es cierto que esta noción nos permite releer su filosofía práctica de cara al discurso contemporáneo sobre la identidad personal (Berti, 2005: 165-168). Hacer esta relectura de la filosofía práctica de Aristóteles no sólo es fundamental para mostrar la vigencia del pensamiento aristotélico y su aplicación a problemáticas contemporáneas, ofreciendo a los filósofos una versión más actualizada de su filosofía,

Todas las referencias a la obra de Aristóteles se citan de la siguiente forma: se alude primer a la edición citada, acorde a los criterios de la revista; posteriormente se añade la referencia canónica. 
sino que también nos permite enriquecer y robustecer la noción de identidad práctica que propone Korsgaard — por ejemplo, enfatizando el papel de la habituación.

Si nuestra aproximación a la noción de identidad práctica es correcta, algo semejante ocurre con relación al pensamiento de Leibniz, ya sea porque en la propuesta del hannoveriano encontramos algunos elementos de la filosofía práctica del Estagirita, como la noción de hábito, o sea porque Leibniz entiende la identidad personal en términos de "cualidad moral", como se aprecia en el diálogo con Locke al interior de sus Nouveaux essais sur l'entendement humain. A pesar de la distancia histórica que separa a Leibniz de Aristóteles, existen diversos pasajes de la obra del hannoveriano donde éste se reconoce deudor del Estagirita en distintos respectos. En relación con su filosofía práctica, en particular, Leibniz reconoce esta deuda en sus Notes sur Aristote redactadas probablemente entre 1662 y 1664, donde sostiene fundamentalmente dos tesis aristotélicas: por un lado, que entre ética y política hay una continuidad; por otro, que "la virtud [se origina] de los actos de elección que hace la voluntad de acuerdo con la recta razón" (Leibniz, 2014c: 192 [Grua, 566])². La noción de identidad personal que el Hannoveriano presenta a lo largo de su obra, tal y como pretendemos evidenciar a lo largo de este trabajo de investigación, se apropia de algunas tesis de la filosofía práctica aristotélica, cara a robustecerla con su teoría de la justicia universal.

Teniendo esto en mente, el presente trabajo de investigación pretende no sólo reconstruir la noción de identidad práctica al interior de las propuestas filosóficas de ambos pensadores, sino también contrastarlas entre sí para mostrar la continuidad entre ambas, así como también identificar algunos puntos en los que difieren. Para lograr este objetivo se ha dividido el presente trabajo de investigación en dos partes: en la primera se analiza la filosofía práctica de Aristóteles a la luz de su noción de praxis y del papel que en esta noción juegan la habituación y la temporalidad, elementos básicos para comprender su caracterización de la agencia moral según Alejandro Vigo; mientras que en la segunda se da cuenta de la dimensión práctica que el hannoveriano adscribe a su noción de identidad personal, tomando como punto de partida tanto su noción de conscientia, como su noción de cualidad moral.

2 Todas las referencias a las obras de Leibniz se citan de la siguiente forma: se añade primero la referencia a la traducción en castellano citada, siguiendo los criterios editoriales de la revista $y$, posteriormente, se añade la referencia al texto original siguiendo las siglas canónicas del autor. En el caso de aquellas citas que son traducción propia, por no contar con una edición en castellano, se cita sólo la edición del texto original. 


\section{HABITUACIÓN, DELIBERACIÓN Y PRAXIS EN ARISTÓTELES}

Es notorio que para Aristóteles los seres humanos son sustancias individuales caracterizadas esencialmente por la racionalidad. A pesar de ello, el Estagirita no deriva totalmente su comprensión del ser humano o, incluso según algunos de sus intérpretes, el mismo estatus de individualidad singular — que hace que cada individuo no sea intercambiable indiferentemente con los demás miembros de su especie_ de la mera racionalidad, sino de aquello que Vigo llama "habitualismo" (Vigo, 2010: 154). Es por ello que el concepto de héxeis tendría entonces un papel importante en la comprensión del ser humano y la individualidad de cada uno de nosotros ${ }^{3}$.

En otras palabras, a pesar de que la noción de sustancia juega un papel central dentro de la filosofía aristotélica, y que "la unidad e identidad especifica del 'yo' personal" se apoya en la forma sustancial de los sujetos de praxis, concretamente en su racionalidad constitutiva, la "individualidad y singularidad esencial al sujeto personal no puede", según Vigo, "derivarse simplemente de su forma sustancial, pues ésta no expresa, como tal, el núcleo íntimo individual de una persona sino sólo lo que ella tiene en común con todos los demás individuos de su especie" (Vigo, 1993: 280).

Es importante evidenciar que esta afirmación es objeto de fuerte polémica. Uno de los problemas más debatidos en la literatura crítica sobre Aristóteles es si la forma es universal o individual (Berti, 2010: 24). En efecto, de acuerdo con una cierta línea de interpretación de Aristóteles, la forma sustancial expresa solamente aquello que tiene en común con todos los demás individuos de su especie. Sin embargo, para autores como Enrico Berti, Terence Irwin, Michael Frede y Günther Patzig, entre otros, la forma en Aristóteles es individual ${ }^{4}$.

Según Berti, "para Aristóteles, el alma no es la especie, sino el principio vital del individuo y es individual como éste” (2005: 163).

\footnotetext{
3 La individualidad singular que distingue a cada hombre es lo que bajo ciertas perspectivas modernas (Locke, Hume, Kant) y contemporáneas (Korsgaard) se ha calificado como identidad personal (Romero, 2016: 282).

4 Como señala Berti (2010: 31), al volver al ejemplo del barco de Teseo en su célebre comentario sobre el libro Z de la Metafísica, Frede y Patzig (2001) sostienen que, si bien su interpretación de la forma como esencia individual es contraria a la tradición de la mayor parte del aristotelismo, esa no carece de precedentes en la exégesis contemporánea de Aristóteles y citan como ejemplo los estudios de Albritton (1957) y Lloyd (1981).
} 
De hecho, esa no es, como se cree a menudo, un principio universal, es decir, lo que une a todos los individuos de una misma especie, aquello que Aristóteles llama en las Categorías "segundas sustancias", es decir, géneros y especies (Aristóteles, 1982 [Cat. 5, 2a 11-19]). Si así fuera, entre las Categorías y la Metafísica existiría precisamente esa flagrante contradicción que muchos han creído encontrar allí, pues en este último tratado Aristóteles consideraría "sustancia primera" precisamente lo que en el primero consideraba "sustancia segunda". En realidad, si la sustancia primera, en la Metafísica, es la forma, y si la forma es el alma, esa es tan individual como el compuesto, es decir, lo que se llamó "sustancia primera" en las Categorías. ¿Cómo puede pensarse, en efecto, que el alma de un solo individuo, por ejemplo, el alma de Sócrates, no sea numéricamente distinta del alma de otro individuo, por ejemplo, de Corisco, aunque ambas sean específicamente idénticas, es decir, ambas sean de la especie racional? Lo que las distingue será ciertamente el hecho de que informan a dos cuerpos diferentes, y por lo tanto su relación con la materia; pero esto no quita el hecho de que sean dos almas numéricamente distintas, y por lo tanto individuales. (Berti, 2005: 162-163)

Siempre según Berti (2010) la individualidad del alma estaría explícitamente sostenida por Aristóteles en diversas partes de la Metafísica y justificada en el De generatione animalium. El autor italiano menciona, por ejemplo, que en el libro Zeta de la Metafísica, Aristóteles afirma que Sócrates y Corisco son "esta alma y este cuerpo aquî" (Aristóteles, 2015 [Metaph., VII 7, 1037a 9]). Y en libro Lambda sostiene que:

También entre las cosas que pertenecen a la misma especie los principios y las causas son diferentes, no diferentes por especie, sino por el hecho de que de individuos cada uno es diferente (tôn kath'bekaston allo), tu (bê te sê) materia, tu forma y tu causa motora son diferentes de la mía (kai hê emê), mientras que por definición universal son las mismas. (Aristóteles, 2015 [Metaph., XII 5, 1071a 28-29])

Berti (2010) añade que un paso importante para resolver el problema relativo a la universalidad o la individualidad de la forma habría sido dado a partir del momento en que ya no se buscó la respuesta del mismo en el libro Zeta de la Metafísica, sino que se tuvo en cuenta la doctrina expuesta en el libro Lambda, según la cual las causas de los individuos son individuales: "el hombre es principio del hombre en general, pero no

\footnotetext{
$5 \quad$ El texto de Berti fue publicado en tres distintas ocasiones, todas ellas en lengua italiana: 1994a, 1994b y 2005. La traducción fue realizada por los autores del presente artículo teniendo por base la publicación del 2005.
} 
existe ningún hombre tal, sino que Peleo lo es de Aquiles, y tu padre lo es de ti" (Aristóteles, 2015 [Metaph. XII 5, 1071a 20-23]).

Profundizar este debate está fuera de los objetivos de este estudio ${ }^{6}$. Sin embargo, Vigo nos ofrece una clave de lectura que evidencia la relevancia de la identidad práctica y del "habitualismo" independientemente del éxito de esta discusión.

(...) aun cuando hubiera que admitir formas individuales, como lo hace Irwin, y sostener entonces que el alma de cada individuo humano es ella misma particular, mi objeción seguiría en pie: con la sola referencia a la particularidad de la forma sustancial no basta para explicar el carácter peculiar que posee la individualidad del "sujeto" de praxis, en términos de lo que exige la noción de identidad práctica, pues lo decisivo aquí seguiría siendo el modo en que, en cada caso, el "sujeto" de praxis se hiciera cargo de su propia identidad sustancial, fundada en su propia forma individual, y no la mera posesión de tal forma individual. A ello se añade que dicho modo de hacerse cargo de la propia identidad sustancial no podría estar determinado él mismo, sin más, por la propia forma individual. (Vigo, 2010: 154-155, nota 29)

Esto significa que la identidad práctica supone en todo momento esta forma sustancial propia de los agentes racionales, como ocurre en el caso de los seres humanos, sin que, por eso, como mencionamos antes, podamos deducir su identidad personal meramente de su forma sustancial.

En efecto, cuando Aristóteles caracteriza al sujeto de la acción como un sujeto de praxis no apela sólo a su forma sustancial, sino prioritariamente a aquellas "disposiciones habituales" $(\text { béxeis })^{7}$ que en su conjunto y unidad configuran su carácter (êthos) ${ }^{8}$. Que la mera presencia de esta racionalidad constitutiva sea insuficiente para configurar el carácter es algo

6 Para una breve discusión del problema de si Aristóteles concibe la forma sustancial, en general, como particular o como universal, Vigo propone el estudio de Rapp (1996). Sobre la base de una interpretación de la crítica al universal platónico que se encuentra en Aristóteles, 2015 [Metaph. VII 13-16], Rapp "sostiene que la forma sustancial es el principio que permite la identificación y la individualización, sin ser ella misma particular, ya que, al mismo tiempo, opera como correlato de la definición y como elemento común a todos los miembros de una especie" (2010: 154, n. 28).

7 Cómo indica Romero (2016), el término béxeis es traducido por Vigo (1996) como "disposición habitual”, por Gadamer (1977) como festen Haltung (actitud firme), y por Heidegger (2008) como "tener junto a sí". Siguiendo los pasos de Romero, si bien nosotros consideramos que las tres traducciones puedan ser acertadas pues resaltan un cierto aspecto del sentido aristótelico, emplearemos la traducción de Vigo.

Para una reconstrucción de la noción béxeis en el Corpus Aristotelicum, véase la investigación ya indicada en la nota precedente, Romero (2016). 
que se hace patente de forma peculiar en la incontinencia (akrasía), donde, contrario al intelectualismo socrático, nos encontramos con un sujeto que, a pesar de poseer juicios moralmente correctos, actúa en contra de lo que juzga mejor para sí (Aristóteles, 1985b [EN, VII, 1145b 21ss.]). La incontinencia, en efecto, es un fenómeno defectivo donde el sujeto de la acción "actúa de modo internamente irracional", en cuanto que "produce habitualmente acciones no conformes con su propio ideal de vida, porque no ha logrado transformar dicho ideal en un ethos" (Vigo, 2016: 159). Esto quiere decir que el incontinente, a pesar de haber elegido deliberadamente seguir un estilo de vida conforme a la recta razón, termina sucumbiendo ante aquello que va en contra de ese ideal, generando una fractura interna (Aristóteles, 1985b [EN, VII, 1145b 12-20]). El incontinente advierte, según Zagal, "que hay un conflicto entre lo que eligió ser y lo que es de facto. Sus acciones concretas no se encaminan hacia la finalidad que él eligió deliberadamente como proyecto de vida. Sus acciones lo alejan de su fin último. Estamos ante una escisión del yo" (Zagal, 2013b: 72). Cara a la escisión interna del sujeto que se da en la incontinencia, Aristóteles incluso afirma que es mejor quien por convicción actúa persiguiendo el placer, que aquel cuyas acciones no se corresponden con el tipo de vida que quiere para sí, ya que éste primero está "mejor dispuesto para la corrección, porque podría persuadírsele a cambiar de actitud" (Aristóteles, 1985b [EN, VII, 1145b 31ss.]).

Una de las características constitutivas de la agencia moral aristotélica, acorde con esta lectura de la incontinencia, reside en la apertura de los sujetos de praxis a la temporalidad, concretamente a un "horizonte de posibilidades futuras" que, al conjuntar "facticidad y posibilidad", "pasado, presente y futuro", escapa a la inmediatez (Vigo, 2011: 283). Los sujetos de praxis aristotélicos, en este sentido, son capaces de proyectarse más allá de la situación concreta de la acción, i.e., el contexto en el que ésta se desarrolla, para deliberar "sobre la base de un proyecto total, más o menos articulado, de aquellas posibilidades futuras que el agente asume en cada caso como propias" (Vigo, 2011: 284). Esto cobra una especial importancia si tenemos en cuenta que el sujeto de la acción se encuentra frecuentemente ante un cierto conflicto desiderativo. Son sus mismos deseos (órexis) los que lo motivan a actuar en términos divergentes o incluso opuestos, ya que su acción responde o bien a ciertos apetitos o deseos no racionales (epitimía) que lo dirigen a la inmediatez, o bien a deseos racionales o conforme a motivos racionales (boúlesis), los cuales suponen este carácter proyectivo (Aristóteles, 1978 [DA, 433b 5-10]). Mientras que los apetitos y deseos no racionales lo mueven a buscar los bienes inmediatos, la mediación racional permite al agente moral tomar 
distancia de lo inmediatamente dado para deliberar cara un horizonte futuro (Vigo, 2011: 285).

Que los agentes racionales sean capaces de proyectarse más allá de su situación concreta, así, "abre la referencia a la representación de la propia vida, como una totalidad temporalmente extendida" (Vigo, 2011: 285), en cuanto que esta mediación racional implica que:

Sobre la base del intelecto práctico y de los deseos racionales orientados por él, se le abre al agente racional la posibilidad de acceso a un horizonte de fines o bienes que no se refieren meramente a la situación presente de acción con la que está confrontado en cada caso, sino que la trascienden y apuntan a la totalidad de la propia vida, considerada como una totalidad temporalmente extendida, que queda abierta a una cierta configuración de sentido. (Vigo, 2011: 286)

Sin la mediación del intelecto, en consecuencia, el placer inmediato aparecería al sujeto como un placer y un bien absoluto o incondicionado (Aristóteles, 1978 [DA, 433b 8-10]), imposibilitando al sujeto de la acción la deliberación sobre el tipo de vida que quiere para sí. Acorde con la filosofía práctica aristotélica, sólo podemos hablar en sentido estricto de praxis bajo el supuesto de que el sujeto de la acción "es capaz de vivir de acuerdo con su propia elección deliberada (proáiresis)" (Aristóteles, 1985a [EE, 1214b 6ss]). La noción de proáiresis, traducida por Vigo como "decisión deliberada", más que hacer "referencia a decisiones o elecciones vinculadas con cursos particulares de acción", alude a una "decisión u opción fundamental por un determinado modo de vida" (Vigo, 2008: 60-61). De ahí que, en opinión de Carlos Pereda, la prudencia aristotélica (phrónesis), y por ende la proáiresis, presuponen "la capacidad de preocuparse no sólo parcialmente, por un área de la vida, por algunos bienes particulares como la salud o la situación económica personal o social, sino por la vida en su conjunto, por decirlo así, por la «totalización" de la vida en tanto «vida buena” (eudaimonia)" (Pereda, 2002: 176). Razón por la cual Aristóteles no duda en afirmar que:

El principio de la acción es, pues, la elección deliberada - como fuente de movimiento y no como finalidad -, y el de la elección es el deseo y la razón por causa de algo. De ahí que sin intelecto y sin reflexión y sin disposición ética no haya elección, pues el bien obrar y su contrario no pueden existir sin reflexión y carácter. La reflexión de por sí nada mueve, sino la reflexión por causa de algo y práctica; pues ésta gobierna, incluso, al intelecto creador, porque todo el que hace una cosa la hace con vistas a algo, y la cosa hecha no es fin absolutamente hablando (ya que es fin relativo y de algo), sino la acción misma, porque el hacer bien las cosas es un fin y esto es lo 
que deseamos. Por eso, la elección deliberada es o inteligencia deseosa o deseo inteligente y tal principio es el hombre. Nada que haya ocurrido es objeto de elección, por ejemplo, nadie elige que Ilión haya sido saqueada; ya que nadie delibera sobre lo pasado, sino sobre lo futuro y posible. (Aristóteles, 1985b [EN, 1139a 31-1139b 8])

Al señalar que la poáiresis es el principio de la praxis, Aristóteles sostiene dos cosas: por un lado, "que en la práxis hay algo más que movimiento (kinesis)", de modo que "la acción humana no es un fenómeno cabalmente natural" (Zagal, 2013a: 94); por otro lado, "que la mera capacidad de producir movimientos voluntarios no debe ser confundida, como tal, con la capacidad de actuar, en el sentido estricto del término" (Vigo, 2008: 61). Esto último se puede ver con mayor claridad en el caso de los niños y los animales, a quienes Aristóteles no considera como genuinos agentes de praxis por carecer de proáiresis (Aristóteles, 1985b [EN, 1111b 5-11]; Aristóteles, 1985a [EE, 1225b 19-29]). Un acto impulsivo, por ejemplo, es un acto voluntario pero que no es fruto de ninguna decisión deliberada (Aristóteles, 1985b [EN, 1111b 10 ss.]). Así, a pesar de que Aristóteles usa el mismo modelo tanto para explicar la producción de los movimientos de los animales y la acción humana, esto es, mediante el silogismo práctico (Aristóteles, 2000 [MA, 700b 17-23]), no por eso deja de reparar en las diferencias entre uno y otro caso, las cuales se aprecian tanto en el aspecto desiderativo de la acción, como en el cognitivo, ya sea porque aluden no sólo a un tipo de deseos, como mencionamos antes al hablar sobre el conflicto en los deseos, sino también porque su acción no queda restringida al ámbito de lo sensible (Vigo, 2008: 62).

Lo propio de los agentes racionales, según Aristóteles, radica en que en todas sus acciones convergen tanto el deseo como el intelecto, entendidos como principios del movimiento, tal y como se sugiere en el Libro III del De anima:

Así, pues, uno y otro -es decir, intelecto y deseo- son principios del movimiento local; pero se trata en este caso del intelecto práctico, es decir, aquel que razona con vistas a un fin: es en su finalidad en lo que se diferencia del teórico. Todo deseo tiene también un fin y el objeto deseado constituye en sí mismo el principio del intelecto práctico, mientras que la conclusión del razonamiento constituye el principio de la conducta. Con razón, por consiguiente, aparecen como causantes del movimiento los dos, el deseo y el pensamiento práctico: efectivamente, el objeto deseable mueve y también mueve el pensamiento precisamente porque su principio es el objeto deseable. (Aristóteles, 1978 [DA, 433a 9-20]) 
A partir de lo cual podemos afirmar, según Vigo, que "las facultades intelectuales y deliberativas propias de los agentes racionales son justamente aquellas que permiten la averiguación de los medios más adecuados para hacer la posible obtención de los fines a los que apuntan sus diferentes deseos" (Vigo, 2008: 62). Esta caracterización de la racionalidad práctica aristotélica, así, presupone que toda genuina acción racional se realiza en función de un cierto fin u objetivo, el cual dota de significación al movimiento corpóreo por el cual es realizada la acción. La concepción aristotélica de la agencia racional, sin embargo, no sólo presupone que existe una pluralidad de fines relacionados a diferentes acciones o actividades particulares, sino también que esa pluralidad de fines particulares se articula en función a ciertas "estructuras teleológicas más comprensivas, dentro de las cuales diversos fines y actividades particulares quedan referidos, en calidad de medios o condiciones necesarias, a otros fines y actividades más importantes" (Vigo, 2008: 64). Esta estructura jerárquica de fines, tal y como observa Zagal, "sólo puede darse si, tarde o temprano, se persigue una finalidad que se quiere en vistas a sí misma, una finalidad que no se desea como medio para conseguir otra cosa", a través del cual podamos "estructurar nuestra vida como una totalidad de sentido" (2013b: 60-61).

La especificidad de la agencia racional aristotélica, por tanto, reside en la capacidad del sujeto de praxis para ordenar cada una de sus acciones particulares a un fin último incondicionado, sin el cual nuestros deseos y la serie de explicaciones que damos a nuestras acciones serían superficiales o banales (Aristóteles, 1985b [EN, 1094a 18-21]). En opinión del Estagirita, el fin último incondicionado que articula y da sentido a la totalidad de las acciones del agente racional es la felicidad, entendida, por tanto, como una representación holística en la que se identifica el obrar bien con el vivir bien (Aristóteles, 1985b [EN, 1095a 15 ss.]), ya que, como sostiene Zagal, "para que la existencia sea una totalidad con sentido, hace falta que el agente se proponga una finalidad última y que, a partir de la consideración y prosecución de tal finalidad, pueda orientar cada una de las acciones de su vida hacia esa meta" (2013b: 68-69). Como afirma Ignacio Yarza, "Si la felicidad humana juega el papel principal en la ética aristotélica, es porque lo hace en la vida de los hombres" (2001: 195). Como argumentado ampliamente por varios intérpretes aristotélicos, no se trata de una imposición o una deducción teórica. La existencia de un fin último no sería una hipótesis gratuita, sino más bien congruente con el estatus existencial y ontológico de la acción humana (Annas, 1998; Abbà, 1995, 1996; Berti, 2004; Yarza, 2001; Samek Lodovici, 2002). 
El hecho de que los hombres no estén de acuerdo sobre el contenido de la felicidad: algunos, por ejemplo, piensan en el placer, mientras que otros piensan en los honores o el dinero, no altera el punto de partida de la ética antigua. Aristóteles no encuentra en la divergencia de opiniones sobre el contenido de la felicidad, un argumento que sí oponga al supuesto de que la felicidad coincida con el objetivo final e integral de todas nuestras acciones. Como argumenta Julia Annas (1998: 33-37), las reflexiones éticas de los filósofos antiguos se inspiran en un proyecto de vida global, donde las necesidades, los bienes y los deberes humanos se conectan y están guiados por ese interés o valor primario, es decir, por esa realidad asumida como central, que está en el corazón del agente y prevalece sobre todas las demás9. Se trata de revisar y organizar los objetivos y prioridades de uno, y cada teoría le pedirá al agente una forma diferente de articular su plan de vida. Sin embargo, la conciliación estructural siempre estará involucrada en cualquier caso una sustancial conciliación entre la búsqueda de la felicidad y la dimensión de la moralidad. Esto significa que las teorías éticas del mundo antiguo, en su precisa dimensión histórico-cultural - son al mismo tiempo teorías morales y teorías de la felicidad, sin fractura y sin dicotomía, en una unidad dinámica. Tanto Annas como el historiador de la filosofía de Giovanni Reale (Annas: 1998: XIV y 597-601) indican que solo los cirenaicos enseñan a renunciar a esta 'visión global' articulada por un fin último, mientras que todas las demás teorías afirman que la tarea de la reflexión ética es comprender y aclarar, en lugar de rechazar, la noción que tenemos del fin último existencial de las acciones que realizamos. (Bastos Andrade: 2019: 21-22)

Nótese que el ordenamiento de cada una de las acciones y fines particulares a un fin último, sin embargo, sólo es asequible al sujeto de praxis en la medida en que sea capaz de forjarse un carácter (êthos), es decir, que adquiera una serie de disposiciones "habituales" (béxeis) conformes a la

9 Annas (1998: 33-37) utiliza aquí el término "filósofos antiguos" para referirse a los autores incluidos entre Aristóteles y Cicerón. En esta investigación sobre el rol metodológico y epistemológico que la eudaimonía (telos) desempeña dentro de la ética antigua, la autora focaliza su estudio en las propuestas formuladas por los escépticos, los cirenaicos, los epicúreos y la Escuela Peripatética. Nótese que no incluye a los sofistas y Platón debido a la imposibilidad de proceder a un tratamiento sistemático de los mismos. Relativamente a los sofistas, señala que el material existente es muy fragmentario y que, en el caso de a Platón, se observa un uso deliberado de la forma dialógica, con el consiguiente rechazo de la discusión sistemática de su propia concepción ética. No existe un diálogo platónico que trate la ética de una manera similar a como lo hace Aristóteles en la Ética a Nicómaco, argumenta, e identificar simpliciter la posición de Platón con lo que dice Sócrates en los diálogos sería algo totalmente ingenuo, arriesgándose a incurrir en el problema de la extrapolación que Annas considera "posible pero muy delicado desde el punto de vista de metodológico y en todo caso más apto para un estudio posterior". 
representación ideal de la vida que ha elegido deliberadamente para sí mismo. A través de estas habitualidades, en consecuencia, es que el sujeto de la acción se hace cargo de su identidad personal (Vigo, 2010: 133) y logra vivir una existencia feliz Samek Lodovici (2002: 13).Las "disposiciones habituales" juegan un papel central dentro de la filosofía práctica aristotélica, en la medida en que constituyen un modo estable de ser, esto es, en palabras de Juliana Valenzuela, una "forma de estar ante el mundo, ante los otros" (2007: 10), a través de la cual el sujeto de praxis configura su carácter. Se trata, en opinión de Vigo, de estructuras de potencialidad adquiridas mediante procesos de habituación —esto es, mediante cierto entrenamiento o ejercicio práctico-, las cuales "constituyen los rasgos definitorios fundamentales de la personalidad del sujeto", de modo que "puede decirse que para Aristóteles el «ser»" mismo del individuo personal es ya, en decisiva medida, un resultado de la propia praxis" (1993: 281). Los hábitos, sean virtuosos o viciosos, no se producen por naturaleza, como ocurre con las disposiciones naturales, sino que son adquiridos como resultado de actividades anteriores: "así", dice Aristóteles, "nos hacemos constructores construyendo casas, y citaristas tocando la cítara. De un modo semejante, practicando la justicia nos hacemos justos; practicando la moderación, moderados, y practicando la virilidad, viriles" (Aristóteles, 1985b [EN, 1103a 32-1103b 1]). Esto significa, tal y como señala Vigo, que:

Las 'héxeis' éticas operan una internalización y conservación de determinados modelos de comportamiento y estándares valorativos, de modo tal que producen una profunda identificación del 'ser' personal del sujeto con tales modelos y estándares: éstos devienen para el sujeto parte de su núcleo personal íntimo, una suerte de 'segunda naturaleza', para usar la expresión tradicional. A partir de dicha identificación, el sujeto de praxis no sólo actúa en adelante de conformidad con tales modelos y estándares, sino además desea de acuerdo con ellos. Esto es: la adquisición y consolidación de determinadas disposiciones habituales éticas no sólo modifica nuestro obrar fáctico presente, sino que influye también decisivamente en el proyecto de nuestro horizonte futuro de expectativas y, con ellos, en nuestro modo de comprender en cada caso la situación presente de acción con la que nos vemos fácticamente confrontados. (1993: 281).

Cuando estas disposiciones habituales, además de ser fruto de una elección deliberada (proáiresis), conducen al sujeto de praxis a actuar en conformidad con la recta razón, esto es, siguiendo los patrones de razonamiento práctico de la persona prudente - en cuanto que el érgon propio de la prudencia es la "verdad práctica" (Zagal, 2013a: 101)_, podemos decir, entonces, que estas disposiciones son virtuosas. La prudencia, 
en efecto, "es un modo de ser racional verdadero y práctico, respecto de lo que es bueno y malo para el hombre" (Aristóteles, 1985b [EN, 1140b 4-5]). De ahí que Aristóteles crea, tal y como sostiene Zagal (2013b: 165), que el ser humano sólo se encuentra habilitado para tener una vida plena, es decir, para ser feliz, mediante la práctica de estas disposiciones virtuosas que nos conducen a buscar la excelencia. La felicidad, según el Estagirita, "es una actividad del alma de acuerdo con la virtud" (Aristóteles, 1985b [EN, 1098a 16 ss.]), bajo el entendido de que "la virtud del hombre será también el modo de ser por el cual el hombre se hace bueno y por el cual realiza bien su función (érgon) propia" (Aristóteles, 1985b [EN, 1106a 21 ss.]). Algo contrario se aprecia tanto en el caso de la persona viciosa como del incontinente, ya que en el primero su carácter (êthos) no encarna un ideal de vida adecuado, conforme a su naturaleza racional, y en el segundo nos encontramos ante un "fenómeno defectivo de dislocación interior", donde el ideal de vida del agente no concuerda con su realidad personal (Vigo, 2016: 17).

A través de la habituación, en este sentido, el sujeto de la acción no sólo construye su identidad práctica, sino que también adquiere cierta consistencia ontológica, la cual permite garantizar cierta continuidad en su ser personal. Con esto queremos decir que la habitualidad, la deliberación y la praxis se encuentran en una relación íntima, cara a la configuración del carácter, pues, tal y como observa Julia Annas:

Quien desee prepararse para realizar lo moralmente correcto, no sólo de modo ocasional sino sistemático, tendrá que desarrollar la destreza y la fuerza mental para vencer las (muchas) tentaciones de hacer otra cosa. En consecuencia, ya no sorprende que la Virtud le advierta a Hércules que su opción es difícil y, a menudo, desagradable y frustrante. Está bien hacer lo que es correcto en el ámbito moral, pero la persona virtuosa debe ir mucho más allá. Tiene que mostrar la disposición, la firmeza para hacerlo. Y al llegar a este punto tiene que haber desarrollado dos cosas: una firme concepción de la moralidad, y la voluntad de actuar en consecuencia. Esto no es ni fácil ni rápido, y cuando alguien logra ser virtuoso tiene que haberse convertido ya en cierto tipo de persona. Por lo tanto, hay una conexión entre la virtud y la vida como un todo: volverse virtuoso es convertirse en una persona con cierto tipo de carácter, y esto demanda reflexionar con profundidad acerca de la vida como un todo y del tipo de persona que aspiramos a ser, así como tener la motivación para continuar en ese camino. Pero esto no va a ocurrir si sólo satisfacemos nuestros deseos y nunca desarrollamos la capacidad para pensar y actuar en el largo plazo. (2000: 73-74)

Téngase en cuenta que esta conexión entre "la virtud y la vida como un todo" es precisamente la conexión entre "la virtud y la vida feliz". 
Cómo afirman Keyes y Annas, si bien Aristóteles "no identifica la eudaimonia con un estado subjetivo de felicidad (feeling good), tampoco cree que esta pueda caracterizarse por una descripción de lo que es objetivamente valioso sin alguna referencia a lo que realmente satisface personas" (2009: 198). En otras palabras, si bien es cierto que la felicidad o la vida lograda en Aristóteles presupone la virtud y, por lo mismo, implica un componente ascético, de esfuerzo por parte del agente, esa misma virtud realiza "aquí y ahora" la felicidad y comporta la satisfacción subjetiva por el fin logrado (Bastos Andrade, 2019: 291) ${ }^{10}$.

Esta posible conexión entre felicidad - horizonte teleológico de la praxis - y virtud - fruto de ciertas disposiciones habituales que constituyen el carácter del agente - ya había formulada por Platón, cuando éste cuestionó "si los justos viven mejor y son más felices que los injustos" (Platón, 1988 [Rep. I, 352 D]). Samek Lodovici (2002) defiende la tesis según la cual Aristóteles fue explícito al afirmar vínculo entre virtud y felicidad: "las acciones según la virtud serán placenteras en sí mismas. Pero ciertamente también serán buenas y hermosas, y en el más alto grado agradables, buenas y hermosas (...). Por eso, la felicidad es al mismo tiempo lo mejor, lo más bello y lo más placentero" (Aristóteles, 1985b [EN, I, 8-9, 1099a 20-25]).

Importantes intérpretes sostienen que, para Aristóteles, la puesta en acto de la naturaleza humana (telos) en el ejercicio de las virtudes constituye la "actividad feliz" o "felicidad". J. Ritter, P. Aubenque, H. Krämer, G. Bien y O. Höffe sostienen que la vida buena es el cumplimiento de este telos, la autorrealización del ser humano ${ }^{11}$. En efecto, Ritter establece

10 La eudaimonía aristotélica no es monista, es poliédrica. La eudaimonía implica satisfacción. La virtud implica satisfacción. Sin embargo, la virtud no es un simple medio para la conquista de un fin último, no es un mero instrumento al servicio de una satisfacción maximizada y/u optimizada. Es una realización concreta de la bondad del fin último "aquí y ahora", en el calor del momento, en la complejidad de las circunstancias, en la belleza de la existencia. Yarza (2001: 151-192) sostiene que la relación "virtud-fin último" consista más en una relación "fines-fin" que en una relación "medios-fin". Se trata de una subordinación o una articulación de fines en un todo armonioso, pero sin que las virtudes se vean reducidas a la única moneda de la satisfacción personal, por lo que no hay monismo. Un sicario que obtiene grandes recompensas (económicas e incluso a nivel emocional) al acechar a matar nunca podrá encarnar la eudaimonía aristotélica (Bastos Andrade, 2019: 291). Para una interesante distinción entre el eudaimonismo aristotélico y el emotivismo humeano, véase: Moss (2014).

11 No faltan los estudiosos de Aristóteles que cuestionan el vínculo entre la felicidad y la virtud. Lodovici (2002: 13-17) menciona, por ejemplo, a A. Kenny, J. L. Ackrill, J. Brunschwig, A.M. Ioppolo y C. Kirwan. Sin embargo, muchos defienden la existencia del tal vínculo. Basado en el estudio del mismo Lodovici, además de Ritter, Aubenque, Krämer, Bien y Höffe, que acabamos de mencionar, se cuentan: K. Held, K. L. Wilkes, 
la relación entre la felicidad y la actividad virtuosa que al ser llevada a cabo construye la vida buena, donde esta última representa la realización de la naturaleza más profunda del hombre Samek Lodovici (2002: 1317). A. Da Re explica que la felicidad "consiste en la realización de uno mismo, que es a su vez una determinada forma de actividad" (1987: 22), donde la autorrealización equivale a un progresivo devenir libre por parte del hombre, que es, en efecto, permanecer "fiel al propio ser, a la propia constitución ontológica" (1987: 23). En síntesis, para Aristóteles, vivir bien es la realización de la naturaleza propia como seres humanos ${ }^{12}$. Sólo que Aristóteles, además, "concibe el 'ser' mismo del agente como el resultado de la propia praxis y esto es posible porque la adquisición de las béxeis no solo influye hasta el punto de modificar el obrar fáctico presente del agente, sino que incide también decisivamente en su proyecto y expectativas futuras" (Romero, 2016: 290).

Finalmente, incluso si los estudiosos de Aristóteles están divididos sobre cuál es la real puesta en acto de la naturaleza humana, es decir, si la actividad de la felicidad es contemplativa o activa, lo que los une en cambio "es la conexión entre la puesta en acto de la naturaleza humana y la felicidad, cualquiera que sea la fisonomía de este último" (Lodovici, 2002: 17). Pero no sólo: como vimos a lo largo de este apartado, la babituación es condición de posibilidad para que se pueda poner en acto lo que somos. En otras palabras, para el Estagirita, vivir bien es la realización de la propia naturaleza humana que se traduce en una acción autoreferencial sostenida en el tiempo que no ocurre sin la deliberación y la habituación.

\section{CONSCIENTIA, REFLEXIÓN E IDENTIDAD EN LEIBNIZ}

En opinión del filósofo de Hannover, la mera habituación es insuficiente para garantizar esta consistencia ontológica de la persona, a no ser que admitamos que esa identidad práctica o moral, junto con el sentimiento o conscientia del yo, "supone la identidad real en cada próximo paso acompañado de reflexión o de sentimiento del yo: pues una percepción intima e inmediata no puede engañar naturalmente" (Leibniz, 1992: 270 [GP V, 219]).

N. Fischer, J. McDowell, A. O. Rorty, J.O Urmson, M. F. Burnyeat, A. MacIntyre, J. Annas, A. Da Re, E. Berti, entre otros.

12 Es conocida la crítica, proveniente de autores analíticos y utilitaristas, según la cual Aristóteles habría cometido un error craso al fundar su ética en una concepción de la naturaleza humana y, por lo mismo, él habría incurrido en aquel célebre tropiezo, cometido también por muchos ingenuos, que invalidaría su propuesta: la falacia naturalista. Se trata de un tema largo y complejo que va más allá de los objetivos de este estudio. Para una breve discusión del problema y defensa de la posición aristotélica, véase: Berti $(1984,1986)$. Para una discusión completa, véase: Szczepanik (2010). 
$\mathrm{Al}$ igual que Aristóteles, Leibniz sostiene que la identidad práctica o personal se distingue de su identidad real u ontológica, a reserva de decir que la primera no puede prescindir de la segunda, ya que ésta, según el hannoveriano, constituye al yo, al cual se le adscribe la causalidad de sus actos intencionales. De ahí también que toda mónada posea una identidad ontológica o real, sin que eso implique necesariamente otro tipo de identidad, como ocurre en el caso de las meras entelequias. En todo caso, sólo puede haber autorreferencialidad si el sujeto de la praxis, previo a la acción, constituye un yo al que se le pueda adscribir esta causalidad. De ahí que podemos inferir un primer punto de encuentro entre Leibniz y Aristóteles, a saber, que en ambos la identidad práctica supone siempre una substancia y, por tanto, una determinada naturaleza individual, entendida como un primer estrato sobre el cual se constituye la identidad práctica o personal. Esto supone, en efecto, que tanto para Aristóteles como para Leibniz, por un lado, la identidad práctica o personal no puede ser deducida directamente de la mera naturaleza racional de los espíritus, a pesar de que, por otro lado, ésta siempre se relacione con un núcleo individual de naturaleza personal que constituye el yo (Leibniz, 1992: 271 [GP V, 219]).

Tomando esto como punto de partida, podemos observar que la lectura leibniziana de la identidad práctica supone un vínculo fuerte entre la naturaleza del individuo y su identidad personal, en cuanto que la primera implica no sólo aquellas determinaciones esenciales o comunes a todos los individuos de la misma especie, sino también aquellas cualidades existenciales y contingentes que lo especifican (Leibniz, 1990: 85 [AA VI, 4B, 1600-1601]). De ahí que Leibniz, acorde con la paráfrasis que hace de Lorenzo Valla, defina persona como "aquella cualidad por la que un hombre difiere de otro hombre, tanto en el alma y en el cuerpo como en las cosas exteriores" (Leibniz, 2010: 107 [AA VI, 4C, 2540]). Esta definición, si mi lectura es correcta, hace justicia tanto a su caracterización de la identidad en términos de completud - la notio completa y la entitas tota (Casales, 2020) —, como a su principio de la identidad de los indiscernibles (Leibniz, 2010: 169 [AA VI, 4B, 1541]; Leibniz, 2010: 328-329 [GP VI, 608]), donde, como sostiene Manuel Sánchez y Neftalí Villanueva, "se entrelazan de forma sistemática metafísica, gnoseología y lógica" (2012: 237). Así, aunque la identidad personal se distingue de la identidad real u ontológica, la primera supone siempre a la segunda.

Acorde con la lectura de Margaret Wilson y Nicholas Jolley, este vínculo entre la identidad personal y la identidad real supone una cierta inconsistencia por parte de Leibniz, en cuanto que es "incoherente suponer que puedo sobrevivir como la misma persona a pesar del cambio en mi identidad 'real' o substancial" (Jolley, 1984: 137; Wilson, 1976: 
347). Esta lectura, sin embargo, no hace justicia a la propuesta leibniziana, en cuanto que pierde de vista dos cosas: por un lado, que el yo al que alude Leibniz al hablar de la identidad real se encuentra tan sólo en un primer estrato del problema de la identidad personal, de modo que esta última no termina por identificarse con la primera; por otro lado, que Leibniz entiende la identidad personal en relación a la cualidad moral del agente racional, la cual se configura mediante la praxis del sujeto de la acción, i.e., en la forma en que el sujeto de praxis se hace cargo ejecutivamente de sí mismo. Mientras que la identidad real del sujeto, configurada por el yo, alude a la entidad completa de la persona; la identidad personal o práctica hace alusión a su agencia racional y el modo en que ésta configura su personalidad. Esta distinción se hace patente en sus Essais de Theodicée, en particular al distinguir entre la inmortalidad de los seres racionales y el ser imperecedero de los animales no humanos:

Sennert y Sperling no se han atrevido a admitir la subsistencia y la indestructibilidad de las almas de las bestias o de otras formas primitivas, aunque las reconozcan como indivisibles e inmateriales. Pero es que ellos confunden la indestructibilidad con la inmortalidad, por la que se entiende que en el hombre no sólo subsiste el alma sino también la personalidad; o sea, al decir que el alma del hombre es inmortal, se hace subsistir lo que hace que sea la misma persona, la cual guarda sus cualidades morales, al conservar la consciencia o el sentimiento reflexivo interno de lo que ella es, y esto la hace capaz de castigo y recompensa. Pero esta conservación de la personalidad no tiene lugar en el alma de las bestias y por esto yo prefiero decir que ellas son imperecederas a llamarlas inmortales. (Leibniz, 2012: 148 [GP, VI, 151])

A reserva de decir que en este trabajo de investigación no ahondaremos en la distinción entre la identidad personal y el yo, sino tan sólo en la dimensión práctica de la identidad, es importante reparar en dos aspectos de su propuesta que ayudan a esclarecer su relación: por un lado, el papel que juega la reflexión y la conscientia en la configuración de nuestra identidad práctica; por otro lado, la relación entre su noción de cualidad moral y naturaleza, la cual es fundamental para entender algunos de sus primeros textos de jurisprudencia. En relación a lo primero, el hannoveriano sostiene en sus Nouveaux essais sur l'entendement bumain que la identidad personal no depende de la memoria, ya que "para encontrar la identidad moral por sí mismo basta que haya un vínculo medio de conciencia" (Leibniz, 1992: 270 [GP V, 219]). A partir de lo cual también afirma que "la identidad real y personal se encuentra de hecho con la máxima seguridad, mediante la reflexión actual e inmediata" (Leibniz, 1992: 271 [GP V, 219220]). No es raro, en consecuencia, que defina la conscientia como "la re- 
flexión sobre una acción, o la memoria de una acción que reconocemos como nuestra" que "incluye la verdadera sustancia misma, o sea, al yo" (Leibniz, 2014: 70 [Couturat, 495]).

Cabe señalarse que el hannoveriano distingue esta conscientia de la mera apercepción sensible, en la medida en que esta última consiste en la mera capacidad de dar cuenta del contenido de algunas percepciones sensibles, mientras que la segunda alude a un acto reflexivo e introspectivo que sólo se da en los espíritus o substancias racionales (Barth, 2011: 216 y ss.; Casales, 2019: 50 y ss.). Esto significa que, a pesar de que el hannoveriano adscribe percepción y apetición a toda substancia simple o mónada, sólo los espíritus "son capaces de llevar a cabo actos reflexivos y de considerar lo que llamamos yo, sustancia, alma, espíritu” (Leibniz, 2010: 346 [Robinet I, 41]). Más aun, Leibniz reconoce que, si bien toda mónada es un espejo viviente del cosmos, "los espíritus son, además, imágenes de la propia divinidad, del autor mismo de la naturaleza, capaces de conocer el sistema del universo y de imitar algo de él mediante diseños arquitectónicos, pues cada espíritu es, en su ámbito, como una pequeña divinidad" (Leibniz, 2010: 340 [GP, VI, 621]). Tesis que se vincula con el segundo aspecto - la relación entre la cualidad moral y la naturaleza-, en cuanto que "la raíz de la libertad humana reside en la imagen de Dios" (Leibniz, 2010: 137 [AA VI, 4B, 1452]).

Dado que sólo los espíritus pueden hacer uso de la razón, de manera que sus actos no siempre siguen un mero impulso o apetito ciego, sino que son capaces de orientar su estructura teleológica interna conforme a su razón, sólo podemos decir que los espíritus son auténticamente libres y, por tanto, susceptibles de responsabilidad moral (Casales, 2018b: 69), sin la cual no podemos hablar de cualidad moral. Acorde con su Nova methodus discendae docendaeque jurisprudentiae, uno de sus primeros textos de jurisprudencia junto con su Codex Iuris Gentium y sus Elementa Juris Naturalis, la cualidad moral de un agente racional tiene sus causas en la naturaleza y la acción: "la naturaleza es la causa de la libertad y la facultad, y de la correspondiente obligación en otro de no impedirla. La acción es la causa de la autoridad sobre una persona que actúa, para hacer o padecer algo actuando sobre sí mismo, o sobre sus bienes” (Leibniz, 2019: 55). Más allá de las implicaciones jurídicas de esto último, resulta interesante señalar que la cualidad moral que propone el hannoveriano implica una relación entre naturaleza, libertad e intencionalidad: los espíritus son libres para actuar intencionalmente por naturaleza. No es raro, en consecuencia, que en este mismo texto defina la cualidad moral de la siguiente forma: 
La moralidad, esto es, la justicia o injusticia de un acto, deriva, sin embargo, de la cualidad de la persona que actúa en relación a la acción que surge de acciones previas, la cual es descrita como cualidad moral. Pero así como la cualidad real es doble en relación a la acción: el poder de actuar y la necesidad de actuar; el poder moral también es llamado derecho, y la necesidad moral es llamada obligación. (Leibniz, 2019: 50)

Al decir que la moralidad del acto deriva de la cualidad del agente moral en relación a sus acciones previas, y que ésta constituye la cualidad moral de la persona, Leibniz está suponiendo que la cualidad moral, al igual que en Aristóteles, supone un proceso de habituación. A este respecto encontramos al menos dos pasajes importantes para entender la noción de hábito que usa el hannoveriano. El primer pasaje se encuentra en su Nova methodus discendae docendaeque jurisprudentiae, donde, siguiendo el De corpore de Hobbes (2000: 265-266), define hábito como "una disposición permanente adquirida para actuar" (Leibniz, 2019: 1), cuya adquisición o causa reside en la impresión que genera un acto sobre nosotros mismos, ya sea de forma extensiva, i.e., la cantidad de veces que se repite un acto, o sea de forma intensiva, es decir, "a la magnitud o fuerza requerida para que el hábito se arraigue” (Leibniz, 2019: 5). La cualidad moral del sujeto de la acción, en consecuencia, está relacionada tanto con la cantidad de repeticiones de un mismo acto, como con la magnitud o fuerza con que estos impresionan nuestra alma, en cuanto que "una acción singular, con una extraordinaria fuerza de impresión es mucho más efectiva que muchas acciones repetidas" (Leibniz, 2019: 7-8).

La segunda referencia la encontramos su De justitia, donde, además de entender al justo como aquel que está "dispuesto a imitar al sabio" para "dirigir la voluntad del hombre" (Leibniz, 2001: 105 [Mollat, 35]), define la caridad en los siguientes términos:

La caridad es el hábito de amar a todos, es decir, una benevolencia general, que, sin embargo, es matizada en sus grados, en razón del objeto. Pero, de por sí, consiste no en el acto, sino en el hábito o en la enérgica inclinación de la mente, que hemos adquirido, bien por suerte en el nacimiento, bien por un singular don de Dios, bien a través de la práctica frecuente. De aquí se sigue que la justicia también será un hábito. (Leibniz, 2001: 106 [Mollat, 36]).

Esta segunda referencia, a diferencia de la primera, nos ayuda a esclarecer la noción de 'disposición', al caracterizar al hábito como una "enérgica inclinación de la mente", donde tanto el aspecto extensivo como el intensivo son fundamentales para generar esa inclinación. Cuando estas disposiciones siguen a la razón, de modo que la praxis va acom- 
pañada de conocimiento, decimos entonces que el hábito es virtuoso (Leibniz, 2001: 423 [Grua, 579]). Siguiendo a Aristóteles, el hannoveriano afirma que la praxis siempre debe ir acompañada del conocimiento "a fin de que el ejercicio de las buenas acciones nos llegue a ser fácil y natural y se convierta en hábito, ya que la costumbre es una segunda naturaleza" (Leibniz, 2001: 425 [Grua, 581]). De ahí que para ser virtuoso y, en consecuencia, feliz, sea "preciso tratar de actuar de modo que nuestro espíritu esté siempre por encima del tema que se ocupa, que reflexione frecuentemente sobre el fin o la meta de sus actos diciéndose a sí mismo de cuando en cuando: ¿qué hago? ¿por qué hago esto?” (Leibniz, 2001: 425 [Grua, 581]). Leibniz, en este sentido, articula una ética de las virtudes, la cual, al igual que en la filosofía práctica del Estagirita, se orienta a la consecución de una vida buena, tal y como se aprecia en las siguientes recomendaciones para alcanzar una vida feliz:

(1) Hay que servirse de la razón tanto como sea posible para conocer los bienes y los males y para discernir los grandes de los pequeños y los falsos de los verdaderos, a fin de juzgar qué será conveniente hacer u omitir durante el curso de esta vida. En una palabra, hay que averiguar lo que la razón ordena, de lo cual procede la sabiduría.

(2) Hay que proponerse firmemente cumplir los mandamientos de la razón, sin que de tan noble designio pueda apartarnos turbación ni pasión alguna. En una palabra, hay que esforzarse por seguir exactamente en la práctica lo que, la teoría, nos enseña la recta razón, de lo cual procede ese hábito que llamamos la virtud.

(3) En fin, habiendo hecho posible por conocer los bienes verdaderos y por llegar a conseguirlos, es necesario estar contento pase lo que pase, y es necesario estar persuadido de que, cuanto está fuera de nuestro poder, es decir, cuanto no hemos podido obtener después de haber cumplido nuestro deber, no forma parte del número de los verdaderos bienes. $Y$, en consecuencia, es preciso, en una palabra, tener siempre el espíritu de sosiego, sin lamentarse de cosa alguna. Y esta disposición del espíritu es la que da la felicidad o tranquilidad del alma. (Leibniz, 2014: 164 [GP, VII, 81]).

A lo cual se le puede añadir el siguiente pasaje de su Guilielmi Pacidii de 1680:

Mas, siga cada cual sus razones; a mí me parece que el varón prudente ha de tomarse un cuidado también de la vida futura (sobre la cual piensan muchos como de un sueño no más y como de paso); y que el hombre ha 
de considerar qué es digno del hombre, qué es lo apropiado a la naturaleza creadora, cómo contribuye a la verdadera perfección y armonía de las cosas al embellecer el propio lote y hacer el bien con la mayor amplitud que pueda cada uno. (Leibniz, 2014: 44 [GP, VII, 124-125])

Esto último supone, en última instancia, dos cosas: por un lado, que la deliberación leibniziana también tiene un carácter proyectivo, el cual le permite al agente racional deliberar o reflexionar sobre el tipo de vida que quiere para sí mismo; por otro lado, que el agente moral leibniziano no sólo delibera sobre su vida futura, sino también sobre la forma en que contribuye, con cada una de sus acciones, a la consecución de la armonía y la justicia universal, ya que, de acuerdo con el hannoveriano, "el espíritu debe figurar siempre en este universo del modo más apropiado para contribuir a la perfección de la sociedad de todos los espíritus que constituye su unión moral en la Ciudad de Dios" (Leibniz, 2010: 248 [GP IV, 486]). Para Leibniz, en efecto, la virtud fundamental es la justicia, entendida no sólo como "la voluntad constante de actuar de manera que nadie tenga razón para quejarse de nosotros", sino también, prioritariamente, como "la caridad del sabio, es decir, una bondad hacia los demás que se ajusta a la sabiduría" (Leibniz, 2001: 90-91 [Mollat, 53-54]).

\section{CONCLUSIONES}

Tomando en cuenta la filosofía práctica de ambos autores, en particular a la luz de la noción korsgaardiana de identidad práctica, es posible observar ciertos elementos comunes que termina por robustecer esta noción. Nos referimos, en primer lugar, a la teoría de la acción que subyace a las propuestas de ambos filósofos, donde el movimiento corpóreo es parte de una acción intención sólo en virtud de aquellas disposiciones internas del sujeto - tanto sus creencias, convicciones y conocimientos, como sus deseos, propósitos e intenciones-, los cuales dotan de significación al acto (Casales, 2018a y 2018b). Aquella efectividad que se da en el movimiento corpóreo de una acción intencional, en efecto, se distingue de cualquier otro en virtud de que ésta se encuentra subordinada a una estructura teleológica de sentido. Esto sólo es posible, en segundo lugar, si el sujeto de la acción es capaz de adscribirse o imputarse la causalidad de sus actos mediante un proceso deliberativo. En el caso específico de Leibniz, esta autorreferencialidad viene garantizada por la relación que establece la conscientia con nuestra identidad real o yo, la cual le permite reflexionar y deliberar sobre sus propios actos. Dada esta capacidad de los agentes racionales para adscribirse la causalidad de sus actos, se sigue que en ambos casos la acción intención encarna siempre una 
razón: lo menos que podemos exigir de un agente racional es que actúe siempre motivado por una razón (Korsgaard, 2017: 92 y ss.).

Aunado a esto, podemos decir que tanto la praxis aristotélica como la cualidad moral leibniziana, en tercer lugar, suponen que aquella identidad práctica o personalidad se configura en virtud de las disposiciones habituales que el sujeto va adquiriendo, a lo largo del tiempo, mediante el ejercicio de sus capacidades activas. En ambos autores, las disposiciones habituales implican una especie de memoria operativa, en virtud de la cual tendemos o nos inclinamos a actuar de tal o cual forma. Cuando estos hábitos siguen a la razón, ya sea mediante la proáiresis, en el caso de Aristóteles, o de la conscientia, en el caso de Leibniz, nos encontramos ante la virtud, la cual nos conduce a la felicidad. A este respecto, sin embargo, encontramos dos diferencias significativas entre Aristóteles y Leibniz: una relativa a su noción de hábito cara a la fragilidad humana; otra respecto a su noción de felicidad. En relación a lo primero es importante señalar que, mientras Leibniz define a los hábitos como disposiciones o tendencias permanentes, Aristóteles además de tener en cuenta la estabilidad del vicio y de la virtud, considera t aquellos casos extremos de fragilidad, como ocurre con Hécuba, cuyo carácter bueno se ve modificado tras la muerte de su hijo menor, Polidoro (Nussbaum, 1995: 491 y ss.). Tener un carácter virtuoso, en este sentido, no significa que la persona no esté sujeta al vaivén de la vida, incluyendo aquellos casos de fragilidad que nos pueden conducir a actuar de forma contraria a lo habitual.

La segunda diferencia se observa en relación a la noción de felicidad de ambos autores, ya que, si bien es cierto que en ambos el agente moral orienta su praxis en función de su ideal de una vida buena, la concepción leibniziana de la felicidad introduce un elemento cristiano, a saber, el espíritu de sosiego que el agente moral debe asumir ante la adversidad. Acorde con la propuesta aristotélica, ser virtuoso no nos hace inmunes a los infortunios o golpes del destino que escapan de nuestra agencia moral: sería ingenuo para Aristóteles creer que quien padece estos infortunios es feliz. No obstante, en Aristóteles la virtud mitiga esos infortunios y, como sostiene Zagal, "los hace más llevaderos" (Zagal, 2013b: 50). En el caso de Leibniz, lo que hace llevaderos a estos infortunios no es la mera virtud, sino aquella "tranquilidad del ánimo" o "contento" que la acompañan, ya que, en opinión del hannoveriano, "mientras estemos en esta situación del ánimo, todo cuanto suceda será lo mejor que nos podía pasar" (Leibniz, 2014: 181 [GP, VII, 99]). Desde la perspectiva leibniziana, por tanto, quien se conduce mediante la razón "no se lamenta nunca del pasado, llegue a alcanzar o no lo que busca; pues si no lo alcanza, acaba viendo que le es más beneficioso no haberlo alcanzado; y lo mis- 
mo que echa en falta, eso mismo le sirve en el futuro para una felicidad más duradera" (Leibniz, 2014: 183-184 [GP, VII, 102]).

Se trata, pues, de una de una "tranquilidad del ánimo" que, si nuestra lectura es correcta, se relaciona íntimamente con la esperanza, en cuanto que ésta se entiende como "la opinión de un bien futuro" (Leibniz, 2014: 91 [Grua, 517]). Esta última, en cuanto que encierra un componente racional o cognitivo, se entiende como un apetito racional que nos motiva a esforzarnos por alcanzar el bien representado, tal y como muestra acertadamente Markku Roinila (2012: 167-170). "Cuando uno tiene esperanza o una expectativa razonada de felicidad como resultado de una vida virtuosa", según Roinila, "uno es motivado a actuar virtuosamente" (2012: 171). Así, en conclusión, mientras que en Aristóteles la virtud nos hace más llevaderos los infortunios de la vida, en Leibniz la vida virtuosa encierra siempre esta esperanza de algo mejor: la esperanza de que no habrá bien que no sea recompensado y mal que no sea castigado.

\section{REFERENCIAS}

Aristóteles. (1978). Acerca del alma. (Calvo Martínez, T., Trad.). Madrid: Gredos Aristóteles. (1982). Categorias. (Candel Sanmartín, M., Trad.). Madrid: Gredos. Aristóteles. (1985a). Ética Eudemia. (Pallí Bonet, J., Trad.). Madrid: Gredos. Aristóteles. (1985b). Ética Nicomáquea. (Pallí Bonet, J., Trad.). Madrid: Gredos. Aristóteles. (2000). Movimiento de los animales. (Alonso Miguel, A., Trad.). Madrid: Gredos.

Aristóteles. (2015). Metafísica. (Calvo Martínez, T., Trad.). Madrid: Gredos.

Abbà, G. (1995). Felicità, vita buona e virtù: saggio di filosofia morale, Roma: LAS.

Abbà, G. (1996). Quale impostazione per la filosofia morale?: ricerche di filosofia morale 1 , Roma: LAS.

Albritton, R. (1957). Forms of Particular Substances in Aristotle's Metaphysics. Journal of Philosophy, (54), 699-708.

Annas, J. (2000). Una brevísima introducción a la filosofía antigua. (Fábregas, J. Ma, Trad.). México: Océano.

Annas, J. (1998). La morale della felicità in Aristotele e nei filosofi dell'età ellenistica. (Andolfo M., Trad.). Milano: Vita e pensiero.

Barth, C. (2011). Leibnitian Conscientia and its Cartesian Roots. Studia Leibnitiana, 43(2), 216-236.

Bastos Andrade, L. (2019). L'eudaimonia nella proposta della psicologia positiva di Martin Seligman. Roma: EDUSC.

Berti, E. (1984). La razionalità pratica tra scienza e filosofia. En Centro di Studi Filosofici di Gallarate (ed.), Il valore: la filosofia pratica fra metafisica scienza e politica (pp. 11-26). Padova: Libreria Gregoriana Editrice.

Berti, E. (1986). A proposito della 'legge di Hume'. En AA. VV., Fondazione e interpretazione della norma (pp. 237-245). Brescia: Morcelliana.

Berti, E. (2004). Filosofia pratica. Napoli: Guida. 
Berti, E. (1994a), "Soggetto, anima e identità personale in Aristotele”, en: G. Severino (ed.), Il destino dell'io, Genova, Il Melangolo, pp. 33-49.

Berti, E. (1994b), "Soggetto, anima e identità personale in Aristotele", en: M. Sanchez Sorondo (ed.), Perì Psychès, De homine, Antropologia: nuovi approcci, Roma, Herder, pp. 1-14.

Berti, E. (2005). Soggetto, anima e identità personale in Aristotele. Nuovi studi aristotelici, 2, 157-168.

Berti, E. (2007). Che cos'è l'anima? Bollettino della Società Filosofica Italiana, (192), 5-16.

Berti, E. (2010). A alma é, para Aristóteles, individual? Hypnos, (24), 24-36.

Casales, R. (2018a). Esbozo de una fundamentación ontológica de la moral en Leibniz. En R. Casales y P. Reyes (coords.), Leibniz en México. Homenaje a Alejandro Herrera (pp. 207-218). México: Torres.

Casales, R. (2018b). Justicia, amor e identidad en la ontología monadológica de Leibniz. Granada: Comares (Nova Leibniz 9).

Casales, R. (2019). Apercepción y conscientia en la ontología monadológica de Leibniz. Véritas, (43), 49-67.

Casales, R. (2020a). Leibniz on Conscientia and personal identity. En D. Herbert, P. Reyes y R. Casales, R. (eds.), Theoretical and Practical Reason in Modern Philosophy. Routledge (en prensa).

Crowell, S. G. (2010). Heidegger on Practical Reasoning: Morality and Agency. En M. A. González y A. Vigo (eds.), Practical Reason. Scope and Structures of Human Agency (pp. 49-74). Hildesheim-Zürich-New York: Georg Olms Verlag.

Da Re, A. (1987). L'etica tra felicità e dovere: l'attuale dibattito sulla filosofia pratica. Bologna: Dehoniane.

Frede, M., \& Patzig, G. (2001). Il libro Z della Metafisica di Aristotele. Milano: Vita e Pensiero.

Gadamer, H. G. (1977). Verdady Método (I). Salamanca: Ediciones Sígueme.

González, A. M. (2018). "Identidad práctica" y moralidad según Korsgaard. Convivium, (31), 177-201.

González-Valenzuela, J. (2007). El ethos, destino del hombre. México: FCE.

Heidegger, M. (2008). Conceptos fundamentales de la filosofía aristotélica. Bloomington: Indiana University Press.

Hobbes, T. (2000). Tratado sobre el cuerpo. (Rodríguez-Feo, J. Trad.). Madrid: Trotta.

Irwin, T. (1988). Aristotle's First Principles. Oxford: The Clarendon Press.

Jolley, N. (1984). Leibniz, and Locke: A Study of the New Essays on Human Understanding. Clarendon: Oxford.

Korsgaard, Ch. M. (2000). Las fuentes de la normatividad. (Lecuona, L. y Manríquez, L. E. Trads.). México: UNAM.

Korsgaard, Ch. M. (2009). Self-Constitution. Agency, Identity and Integrity. New York: Oxford University Press.

Korsgaard, Ch. M. (2011). La creación del reino de los fines. (Granja, D. M. y Charpenel, E. Trads.). México: UNAM. 
Korsgaard, Ch. M. (2017). Actuar por una razón. Anuario filosófico, 50(1), 87-118. Leibniz, G. W. Sämtliche Schriften und Briefe, von der Deutschen Akademie der Wissenschaften zu Berlin, Darmstadt (1923 y ss.), Leipzig (1938 y ss.), Berlin (1950 y ss.).

Leibniz, G. W. (1948). Textes inédits d'après les manuscrites de la bibliothèque proviciale de Hannovre, publiés et annotés par G. Grua, Paris.

Leibniz, G. W. (1954). Principes de la nature et de la grâce fondés en raison. Principes de la philosophie ou monadologie, publiés intégralement d'après des lettres inédites par Robinet, A., Paris.

Leibniz, G. W. (1961). Opuscules et fragmentes inédits de Leibniz. Extraits des manuscrits de la Bibliothèque royale de Hanovre, par L. Couturat, Hildesheim.

Leibniz, G. W. (1965). Die Philosophischen Schriften. herausgegeben von C.I. Gerhardt, Hildesheim.

Leibniz, G.W. (1893). Mitteilungen aus Leibnizens ungedrucken Schriften, von G. Mollat, Leipzig.

Leibniz, G. W. (1990). G. W. Leibniz. Escritos en torno a la libertad, el azar y el destino. (Roldán Panadero, C., ed.). Madrid: Tecnos.

Leibniz, G. W. (1992). Nuevos ensayos sobre el entendimiento humano. (Echeverría, J., Trad.). Madrid: Alianza.

Leibniz, G. W. (2001). Escritos de filosofía política y jurídica. (de Salas, J., ed.). Madrid: Biblioteca Nueva.

Leibniz, G. W. (2010). G.W. Leibniz. Obras filosóficas y cientificas. 2. Metafísica. (González, A. L., ed.). Granada: Comares.

Leibniz, G. W. (2012). G. W. Leibniz: Obras filosóficas y cientificas. 10. Ensayos de Teodicea. (Guillén Vera, T., ed.). Granada: Comares.

Leibniz, G. W. (2014). Methodus Vitae (Escritos de Leibniz). Vol. III: Ética o política. (Andreu, A., Trad.). Madrid: Plaza y Valdés.

Leibniz, G. W. (2019). The New Method of Learning and Teaching Jurisprudence. According to the Principles of the Didactic Art Premised in the General Part and in the Light of Experience. (Massimo, C., ed). New Jersey: Talbot.

Lloyd, A. C. (1981). Form and Universal in Aristotle. Liverpool: Francis Cairns.

Moss, J. (2014). Was Aristotle a Humean? A Partisan Guide to the Debate. En R. M. Polansky (ed.), The Cambridge Companion to Aristotle's Nicomachean Ethics (pp. 221-241). Cambridge: Cambridge University Press.

Nussbaum, M. (1995). La fragilidad del bien. Fortuna y ética en la tragedia y filosofía griega. Madrid: Visor.

Pereda, C. (2002). Sobre el concepto de Phrónesis. Thémata, (28), 175-186.

Platón. (1988). República. (Eggers Lan, C., Trad.). Madrid: Gredos.

Rapp, C. (1996). Kein Allgemeines ist Substanz (Z 13, 14-16). En C. Rapp (ed.), Metaphysik. Die Substanzbücher (Z,H,Q). Berlin.

Roinila, M. (2012). Leibniz on Hope. En S. Ebbersmeyer (ed.), Emotional Minds: The Passions and the Limits of Pure Inquiry in Early Modern Philosophy (pp. 161177). Berlin: De Gruyter. 


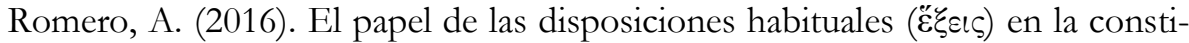
tución de la identidad práctica bajo la perspectiva aristotélica. Azafea. Revista de filosofía, (18), 281-291.

Samek Lodovici, G. (2002). La felicità del bene, Filosofia. Milano: Vita e pensiero.

Sánchez Rodríguez, M. \& Villanueva Fernández, N. (2012). El fundamento lógico-metafísico de la identidad personal en la filosofía de Leibniz en torno a 1686. Análisis, influencia y revisiones. Thémata. Revista de Filosofía, (46), 237-245.

Vigo, A. (1993). Persona, hábito y tiempo. Constitución de la identidad personal. Anuario Filosófico, (26), 271-287.

Vigo, A. (1996). Zeitund Praxis bei Aristoteles. Freiburg: K. Alber.

Vigo, A. (2008). Prâxis como modo de ser del hombre. La concepción aristotélica de la acción racional. En G. Leyva, Filosofía de la acción. Un análisis histórico-sistemático de la acción y la racionalidad en los clásicos de la filosofía (pp. 53-85). Madrid: Síntesis.

Vigo, A. (2010). Identidad práctica e individualidad según Aristóteles. Hypnos, (25), 129-164.

Vigo, A. (2011). Razón práctica y tiempo en Aristóteles. Futuro, incertidumbre y sentido. En A. Vigo, Estudios aristotélicos (pp. 279-300). Pamplona: EUNSA.

Vigo, A. (2016). Identidad práctica y reconocimiento. El debate contemporáneo y el modelo fichteano. Metafísica y persona, (15), 11-46.

Szczepanik, W. (2010). From Hume's Passage on 'Is" and "Ought” to Anscombe's Response to the "Is-Ought" Question. Roma: EDUSC.

Wilson, M. (1976). Leibniz: Self-Consciousness and Inmortality in the Paris Notes and After. Archiv für Geschichte der Philosophie, 58(4), 225-352.

Yarza, I. (2001). La razionalità dell'etica di Aristotele: uno studio su Etica Nicomachea I. Roma: Armando.

Zagal, H. (2013a). Apetito recto, prudencia y verdad práctica. Las pautas de la eupraxía en la Nicomáquea. Metafísica y persona, (9), 91-111.

Zagal, H. (2013b). Felicidad, placer, virtud. La buena vida según Aristóteles. México: Ariel. 